Canadian University Music Review

Canadian University Music Review

Revue de musique des universités canadiennes

\title{
Post-World War II Rhythm and Blues: Jump Blues, Club Blues, and Roy Brown
}

\section{Rob Bowman}

Volume 17, numéro 1, 1996

URI : https://id.erudit.org/iderudit/1014691ar

DOI : https://doi.org/10.7202/1014691ar

Aller au sommaire du numéro

\section{Éditeur(s)}

Canadian University Music Society / Société de musique des universités canadiennes

\section{ISSN}

0710-0353 (imprimé)

2291-2436 (numérique)

Découvrir la revue

Citer cet article

Bowman, R. (1996). Post-World War II Rhythm and Blues: Jump Blues, Club Blues, and Roy Brown. Canadian University Music Review / Revue de musique des universités canadiennes, 17(1), 20-39. https://doi.org/10.7202/1014691ar

\section{Résumé de l'article}

The classification of different styles of North American popular music has often been problematic. This paper investigates some of the music referred to as rhythm and blues ( $\mathrm{r} \&$ b) in the late 1940 s and early 1950 s by specifically looking at the works of one of the music's leading practitioners of the time, Roy Brown. Brown recorded both jump and club blues between 1947 and 1955, placing fifteen records in the Top 20 of the Billboard rhythm and blues charts. For the purposes of this paper fifty-four of the seventy-four songs that Brown recorded in this period were analyzed with respect to structure, performing force, performance style, tempo, arrangement, bass lines, approach to the beat, rate of singing, vocal ornamentation, and lyric content and structure. Three main subdivisions were found within Brown's repertoire, all connected to social behaviour, namely, dance. In the process, a basic biography of Brown is provided and his influence on many subsequent rhythm and blues and rock and roll performers is contextualized.
All Rights Reserved @ Canadian University Music Society / Société de musique des universités canadiennes, 1996
Ce document est protégé par la loi sur le droit d'auteur. L’utilisation des services d'Érudit (y compris la reproduction) est assujettie à sa politique d'utilisation que vous pouvez consulter en ligne.

https://apropos.erudit.org/fr/usagers/politique-dutilisation/ 


\section{POST-WORLD WAR II RHYTHM AND BLUES: JUMP BLUES, CLUB BLUES, AND ROY BROWN}

\section{Rob Bowman}

The classification of different styles of North American popular music has often been problematic. For example, what is rock as opposed to rock and roll? Is Bill Haley a rockabilly artist, a practitioner of Northern band rock and roll, or something altogether different? ${ }^{1}$ Classifying post-World War II black secular popular music is equally problematic. The phrase rhythm and blues was in general currency from 1949 through the mid-1960s as an all-encompassing classification, when it was replaced with the term soul. In present day use, rhythm and blues has become the umbrella phrase encompassing the gamut of black popular music-such as funk, disco, house, rap, and go go-in the post-war era, much as the term jazz is used to embrace a tradition that covers the spectrum from the New Orleans style of King Oliver's Creole Jazz Band through the avant garde gestures of Anthony Braxton. It is the music referred to by the earlier use of the term rhythm and blues, the music of the late 1940s and early 1950s, that this article investigates, looking specifically at the works of one of the music's leading practitioners, Roy Brown.

Before looking in detail at Brown's style and career up to 1955, however, it is necessary to look at the context of black popular music in the early post-war years. There were a number of sociological, industrial, and technological conditions necessary for the rise of post-war rhythm and blues. The first of these was the massive shift of the black populace during the war years from rural to urban living. Four hundred thousand African Americans (Roy Brown and Charles Brown among them) migrated to Watts alone during these years. This newly urbanized populace almost immediately enjoyed substantially increased purchasing power (albeit conditions and pay were still significantly below the standards of the white work force). Entertainment was an obvious outlet for this newfound wealth. The rural to urban shift affected much more than employment opportunities; it effectively created new values, needs, and life experiences. Since new social conditions demand new expressive forms this necessitated a fresh style of popular music that would reflect these new realities. $^{2}$ The music that arose to meet these socio-economic changes-jump blues and club blues on the West Coast and what Charlie Gillett has termed bar band blues in Memphis and Chicago-had little chance of being recorded,

1 "Northern band rock and roll" is a phrase coined by Charlie Gillett in his excellent book The Sound of the City: The Rise of Rock and Roll (London: Souvenir Press, 1983).

2 See Elie Siegmeister, Music and Society (New York: Haskell House Publishers, 1974). 
promoted, or disseminated by the major record companies. After the Depression of the early 1930s, these companies had been generally unreceptive to musics primarily consumed by African American peoples. It is easy to look at this and cry racism. This probably did play a part, consciously or subconsciously, in some of the decisions made by the artists and repertoire (a \& r) departments of major labels, ${ }^{3}$ but their lack of receptivity was largely a factor of economic policy and social distance. Although the black populace made up approximately ten per cent of the population of the United States at the time, its economic level did not reflect this. As far as major labels were concerned, there was simply not enough purchasing power within the black community to make recording black artists financially worthwhile. In addition, major label a \& $\mathrm{r}$ personnel tended to be white and middle class. They had little contact with or knowledge of the black community and its aesthetic ideals and were not equipped to judge one artist from another, let alone have any idea of who might sell or in what quantities. With the notable exception of Decca Records, the major companies tended to avoid rhythm and blues.

This left the rhythm and blues field open to independent record labels which proliferated in the immediate post-war years. Many were spurred by the success of Gilt Edge Records, ${ }^{4}$ whose very first release in 1944, Cecil Gant's "I Wonder," became a number one rhythm and blues hit and a number twenty pop hit, ${ }^{5}$ selling close to one million records. The development of the independent companies was facilitated by the war-time invention of the open reel tape recorder which was relatively inexpensive and much less cumbersome than the earlier direct-to-disc method of recording. With many blacks, especially in rural areas, unable to afford large numbers of records, the jukebox became extraordinarily popular during the war years, providing a relatively cheap outlet for the regular consumption of new releases. Indeed jukebox technology was instrumental in the survival of most independent record companies that specialized in black popular music. Because breakage of seventy-eights was a common phenomena jukebox operators would buy several copies of a given popular record boosting sales even more. New technology in the form of the electric guitar and microphone also directly influenced post-war styles. The electric guitar was developed in the 1930s and came into common usage as the war came to an end in 1945. This instrument created new possibilities for tone, sustain and volume control. The microphone facilitated the development of very different singing styles, including the talking and subdued vocal forms of jump blues and club blues respectively, as singers no longer needed to shout to be heard above the band.

${ }^{3}$ The a \& $\mathrm{r}$ department is responsible for signing artists to the label and then for matching artist, producer, and repertoire when it is time for a recording session.

4 Arnold Shaw, Honkers and Shouters: The Golden Age of Rhythm and Blues (New York: Collier, 1978), 89.

5 All chart positions refer to those listed on the various Billboard charts. They are taken from Joel Whitburn, Top R \& B Singles, 1942-1988 (Menomonee Falls, Wisc.: Record Research, 1988) and Joel Whitburn, Pop Memories, 1890-1954 (Menomonee Falls, Wisc.: Record Research, 1986). 
Like most styles, post-war rhythm and blues had important antecedents that predate the period of intense style-defining activity, but it is generally considered to have developed and coalesced during World War II with a handful of significant recordings, (Louis Jordan's first hits and Private Cecil Gant's ground breaking record "I Wonder," for example) being issued during the war period itself. Jordan and Gant were seminal figures. The former introduced what is commonly referred to as jump blues while Gant released the first example of what was later termed club blues. The majority of Roy Brown's recordings fall into these two categories. ${ }^{6}$ Both these styles had precursors. Jump blues bands such as Jordan's Tympany Five evolved from the big bands which had been extraordinarily popular from the late 1920s through the end of the World War II. Jordan, himself, had been playing alto saxophone and singing novelty numbers opposite Ella Fitzgerald with the Chick Webb Band from 1936 to 1938.

Charlie Gillett describes the jump blues style as follows:

Typical jump blues combos featured a strong rhythm section of piano, guitar, bass and drums, and usually had a singer and a saxophonist up front, with sometimes a second sax man added. Between them, the various instrumentalists emphasized the rhythm that a boogie pianist had achieved alone with his left hand, and in the process of transcribing the effect to several instruments the difference between each beat was either emphasized more-in jump rhythms-or blurred in shuffle rhythms. Several different regional variations of the style developed, in New York, on the West Coast, in the mid-South (St. Louis/Memphis), in New Orleans, in Chicago, and on the Eastern Seaboard. ${ }^{7}$

There are a number of points here that need correction or amplification. Gillett's references to regional variants in the mid-South and Chicago and his comments on the presence of a shuffle rhythm, indicate that he includes performers such as Sonny Boy Williamson II and Howlin' Wolf in this category. These artists would be more appropriately included in his bar band blues style alongside Muddy Waters and John Lee Hooker, who performed what most writers refer to simply as post-war urban blues. I would take issue also with the distinction Gillett makes between jump and shuffle rhythms. The boogie or shuffle rhythm pervaded the jump style. This rhythm, played by a walking bass and piano, often eight-to-the-measure, was not new. ${ }^{8}$ It was heard regularly in a band context played by exponents of the Kansas City style of swing music out of which Jordan emerged. Of equal importance with the walking bass and shuffle rhythm was an overall approach to time that can best be described as light (crisp, staccato and with little intensity or sustain), uptempo (there was no such thing as a slow jump tune) and on top, or slightly

6Both terms are used by Charlie Gillett and Arnold Shaw, the only two writers to attempt book length histories of rhythm and blues in the 1940s and 1950s.

7 Charlie Gillett, The Sound of the City, 133.

8 Some tend to think of a walking bass as strictly four quarter notes to the measure. In this style, it is common for the bass to play a four-to-the-measure pattern while the left hand of the piano will play an eight-to-the-measure gapped-triplet pattern simply repeating every note that is being played on the bass. 
ahead, of the beat. ${ }^{9}$ Contrary to what Gillett says a trumpet was nearly obligatory in the jump style while, until the late 1940s, guitar was rarely used. There are a number of additional characteristics that Gillett fails to note. Structures were generally based around eight- and twelve-measure sections. Both vocalists and instrumentalists used a combination of triplet and binary divisions of the beat. Finally, the two- or three-horn front line usually played contrapuntal riffs, which served the function of fills around the vocalists and instrumental soloists, and the piano usually doubled the bass line with the left hand, while playing high staccato boogie fills with the right hand.

Jump combos often featured a number of humorous, "slice-of-life" songs such as Jordan's "Saturday Night Fish Fry," "No One Here But Us Chickens," and "This Chick's Too Young to Fry" that were full of then hip jargon. As often as not these songs addressed one of the exigencies of heterosexual love with texts that self-referentially mentioned the "boogie" style of music. Jump vocalists tended to be much less involved emotionally (at least as measured by the use of playful voicedness and timbral variation) than the more down home urban singers such as Elmore James and Howlin' Wolf. Louis Jordan always sounded somewhat detached and amused, often half-talking his way though his material. As well, jump vocalists tended to clearly enunciate the lyrics to their songs, enabling some, such as Jordan, to be popular with white as well as black audiences. Jordan's "Choo Choo Ch'Boogie," recorded in January of 1946 for Decca, can serve as a typical example of jump blues. Its eight- and twelve-bar structures can be seen in the following diagram:

$\begin{array}{ccccccccccc}\text { Intro } & \text { Verse } & \text { Chorus } & \text { Piano Solo } & \text { V } & \text { C } & \text { Alto Sax Sol } & \text { V } & \text { C } & \text { Tpt/Sax } & \text { Tag } \\ 12 & 12 & 8 & 12 & 12 & 8 & 12 \& 8 & 12 & 8 & 8 & 2\end{array}$

Both the bassist and the left hand of the pianist play a walking eight-to-themeasure figure in a shuffle rhythm, while the guitarist and drummer, the latter employing brushes, play on every quarter beat. The bass, guitar and piano are playing ever-so-slightly ahead of the beat articulated by the drums. The tempo (quarter note $=162$ ) is very suitable for dancing. Riffs played in rhythmic unison by trumpet, alto and tenor saxophone serve as fills between the vocal phrases and occur throughout each verse as well as during the alto saxophone solo. Quarter note triplets are heard prominently in $\mathrm{mm} .7$ and 8 of the tag. Jordan virtually talks his way through the lyrics with every word being clearly enunciated. The lyrics fit the mould of the clever, somewhat humorous, happy "slice-of-life" vignettes cited above:

Gonna settle down by the railroad track

And live the life of Riley in a beaten down shack.

So when I hear a whistle I can peak through the crack

And watch the train a-rollin' when it's ballin' the jack.

${ }^{9}$ The famous Count Basie rhythm section of Basie (piano), Freddy Green (guitar), Walter Page (bass), and Jo Jones (drums) was probably the finest and most influential of the early progenitors of this rhythmic approach. 
For I just love the rhythm of the clickety-clack

So take me right back to the track Jack. (third verse)

The style of the alto saxophone solo deserves comment. Jordan's gritty tone stands in marked contrast to the rest of the performance which is dominated by much less abrasive timbres. It must be remembered that cool sophistication was the ideal for this style. Practitioners and consumers of this genre were an urbane subculture who generally found the involved styles of straight blues performers such as Muddy Waters and Sonny Boy Williamson II somewhat distasteful, perhaps a little too reminiscent of a not-too-distant past.

It is important not to lose sight of the fact that jump blues was first and foremost a popular dance music. To a large degree, it arose as a small combo offshoot of Kansas City swing and can be viewed as a reaction to the ascendancy of bebop, a new style of jazz that was considered to be on the cutting edge in the early 1940s. Prior to the war, dance blues were played by big band jazz ensembles. The war severely reduced several of the larger bands and a number of the resulting smaller ensembles turned to playing bebop. ${ }^{10}$ Bebop's jagged, angular melodies were the antithesis of the singable and instantly memorable ones of most popular material. Here was a music that deliberately precluded the participation of large numbers of musicians and listeners and which effectively spelt the end of jazz as a popular music on a mass scale. Louis Jordan, for one, recognized this and stated often that bebop musicians "play mostly for themselves. I want to play for the people."11 Jordan was evidently successful at this since his brand of jump blues proved to be extremely popular. Between October 1942 and May 1951, fifty-seven of his records entered the Top 20 on Billboard's rhythm and blues charts.

Equalling the jump blues in popularity was the style pioneered by Cecil Gant known as club blues.

While the jump blues served to express whatever confidence people felt on the West Coast during and after the war, the quieter club blues expressed the more dominant mood there, one tinged with despondency ... Living conditions and earnings in the West Coast cities-mainly Los Angeles and Oakland-were much better than they had been in Texas, but were still much worse for blacks than for whites working alongside them. During the war, the migration of blacks into California outpaced the provision of special facilities for them, so that for some years they shared the nightclubs with the whites. The unusual integrated audience may have encouraged the black singers to minimize the blues content of their repertoire. In any case, "cocktail" piano playing was common-pretty right-hand tinkling with a light rhythm from bass and brushed drums. The club customers didn't like their conversation to be drowned by the music, so the singers

10The big bands were depleted for a number of reasons. Musicians were drafted and opportunities to record decreased due to the government rationing of shellac and electronic parts and because of the musicians union strike. Govemment rationing severely restricted the activity of the whole record industry but, as is par for the course, independent labels and African American music were affected disproportionately more.

11 Shaw, Honkers and Shouters, 62. 
and musicians had to develop a style that instilled a mood without requiring that all the words be heard. ${ }^{12}$

Nat King Cole was probably the first to develop this style but, in the main, he was neither a blues nor a rhythm and blues singer. Instead Cole represents an ersatz, jazz-influenced style that sold more to whites than it did to blacks. Consequently, it makes more sense to cite Cecil Gant as the first artist with a rhythm and blues hit and Cole simply as a precursor, with Charles Brown as the major, most popular and ultimately most influential practitioner in this style.

Charles Brown, the pianist and lead singer with Johnny Moore's Three Blazers, started his run of hits in 1945 with "Drifting Blues." His songs were invariably set to a slow tempo with his voice and piano being accompanied by restrained guitar, bass and sometimes a saxophone. "Brown exemplified the fact that to a greater extent than ever before blues singers had become narcissisticly preoccupied with the depths of their misery, seemingly unable to find cause for hope or gladness." ${ }^{13}$ His first hit, the 1945 recording "Drifting Blues," provides an example of a typical club blues lyric.

Well I'm drinking and drifting like a ship out to sea (twice)

Well I ain't got nobody in this world to care for me.

If my baby would only take me back again (twice)

Well you know I ain't good for nothin' baby, well I haven't got no friends.

I'll give you all my money, tell me what more can I do? (twice)

Well you just ain't no good little girl, but you just won't be true.

Bye bye baby, baby bye bye

It's gonna be too late, I'll be so far away.

Brown sings this lyric with the same reserved, melancholy quality that he uses for a joyous lyric such as "Merry Christmas Baby," in both cases betraying little naked emotion. The Three Blazers' "Merry Christmas Baby," featuring Charles Brown as lead vocalist and pianist, was a substantial hit in 1947, 1948, and 1949 for the Los Angeles-based Exclusive Records and provides a typical example of this style. Its structure is as follows:

$\begin{array}{ccccc}\text { Intro } & \text { Verse } & \text { Verse } & \text { Guitar Solo } & \text { Verse } \\ 4 & 12 & 12 & 12 & 12\end{array}$

As with jump blues, the twelve-measure form dominated club blues but introductions were usually shorter due to the slower ballad-like tempo that was also a central defining characteristic of the form. "Merry Christmas Baby" is set at quarter note $=90$. No drums are present, the bass plays on beats one and three, consistently right on the beat, rather than slightly ahead of it as was the case with jump blues, and Johnny Moore's electric guitar is quite restrained, utilizing the typical jazz timbre pioneered by Charlie Christian on his 1939-41

12Gillett, The Sound of the City, 142-43.

13 Ibid., 143. 
Benny Goodman recordings. Characteristically, the piano (celeste in the introduction and first verse to emphasise the seasonal nature of this example) dominates the track, providing the response to the voice with high-end blues fills in the right hand while the left hand simply duplicates the bass line. Despite the joy exemplified in the lyric, Brown's voice is subdued. As with jump blues, the style of singing does not change with the lyric, since this also was music for a sophisticated urban audience for whom a display of too much emotion would perhaps have been considered embarrassing; a lack of control that was too reminiscent of the rural areas from which most of this audience had just recently escaped. ${ }^{14}$

Several post-war rhythm and blues artists, including Roy Brown, recorded in both the jump and club blues styles, but these particular forms of West Coast popular music have unfortunately been largely ignored by both scholars and hobbyists. Blues research has historically been dominated by the somewhat racist, or at least romantic, idea of purism. Many early researchers considered music as sophisticated as jump and club blues to be sullied and therefore not worthy of sustained attention. Their research focused instead on pre-war forms and the post-war Chicago, New Orleans and Memphis manifestations of Delta blues. Since many of these researchers were also involved, in the 1960s and early 1970s, in legitimate and bootleg reissue programs by both major and independent record labels, very little jump or club blues material was made available during the heyday of the blues revival. Instead a plethora of Chicago bar blues material was reissued. This had an inordinately large effect on the history of popular music. Most readers will be familiar with the music of the British Invasion bands from 1963 to 1966 such as the Beatles, the Rolling Stones, the Animals, the Who, the Kinks, and the Yardbirds. These bands covered numerous recordings of African American post-war rhythm and blues artists and their overall style was very directly shaped by this music, ${ }^{15}$ but they were primarily interested in the bar band blues of Memphis and Chicago. It is telling that between them there is not one example of a jump or club blues cover. This is a direct result of the interests and tastes of the initial blues researchers, namely the guitar and harp-dominated Delta and urban traditions in Memphis, Chicago, and later New Orleans. It was these traditions that were constantly discussed in print, these artists who were brought over to Europe for concert appearances and these artists whose recordings were reissued. British musicians coming of age in the late 1950s and early 1960s remained mostly unaware of jump and club blues, and a later generation of North Americans and Europeans, who grew up listening to the British Invasion and later to the blues revival bands, consequently heard and learned nothing about jump and club blues. Neither the bands nor the scholars that came out of this second, 1960s-early 1970s generation addressed these styles in either performance or research, and this served to further perpetuate an exceedingly dis-

14 See Louis Wirth, "Urbanism as a Way of Life." American Journal of Sociology 44, no. 1 (July 1938): 1-24, for a still influential account of the differences between the rural and urban mindset.

$15 \mathrm{~A}$ cover is a recording of a given artist's song by a second artist. 
torted concept of urban black popular music from the 1940s through the late 1950s. As late as 1975 artists such as Louis Jordan were relatively unknown and their records, for the most part, were totally unavailable. ${ }^{16}$

Having provided some context for black popular music of the early post-war years we can turn now to the career and music of Roy Brown. Brown's recording career, for all intents and purposes, started in 1947 with Deluxe Records. ${ }^{17}$ When Deluxe was sold to the Cincinnati-based King Records in 1950, Brown recorded for King until he was released from his contract in 1955. He then recorded for Imperial, Home of the Blues, DRA, Connie, Mobile, Chess, Bluesway, Gert, Summit, Tru-Love, Epic, Friendship, and Mercury. These post-1955 recordings, however, fall outside the scope of this article. They represent a substantial change in style as Brown and his contemporaries attempted to come to terms with the emergence of a new form of rhythm and blues which would become known as rock and roll. Brown recorded both jump and club blues between 1947 and 1955, roughly the years that these styles were current, becoming one of the most popular rhythm and blues artists in North America. He placed fifteen records in the Top 20 on the Billboard rhythm and blues charts between 1948 and 1951, and won the Metronome Award for the most booked combo in the United States every year from 1947 to $1951 .{ }^{18}$

Brown was born 10 September 1925 in New Orleans. His mother was the choir director, soloist and organist at a local Baptist Church. Much of his youth was spent moving around rural Louisiana as his family followed whatever work opportunities came the way of his father, a bricklayer and plasterer. Later, as a young teenager, Brown worked chopping sugar cane, picking cotton and harvesting rice. At the time, he says, blues were not a prominent part of life in rural Louisiana. Instead he grew up on a steady diet of spirituals, ${ }^{19}$ inspiring him at the age of thirteen to organize his own spiritual quartet called the Rookie Four Gospel Quartet. ${ }^{20}$ Even at this early age he was writing some of his own material. One such original composition, "Satan's Chariots Rolling By," led to Brown being chastised by his mother for "jazzing up the spirituals." ${ }^{21} \mathrm{His}$ father had deserted the family when Brown was quite young, so that when his mother died in 1939, he found himself on his own. Barely fourteen, he moved further west to Houston where he attended high school. It was in Houston that he first heard the blues shouting of singers such as Wynonie Harris, who at the time was appearing at local dances with the Lucky Millinder Band. ${ }^{22}$ Three

16 In the last ten years, much of this has changed at least in the area of compact disc reissues. Various single CDs have been released featuring individual performers including Roy Brown and, in the most impressive case, Bear Family Records in Germany in 1992 issued a nine-CD box set of Louis Jordan's complete recordings for Decca (Bear Family BCD 15557).

17 Brown was first recorded in 1946 by Bill Quinn for the Gold Star label, but this was an unauthorized bootleg recording that was not issued until 1947, after the success of his first legitimate release.

18 Jonas Bernholm, liner notes for Roy Brown, 1925-1981: Saturday Night (Sweden: Mr. R \& B Records, 1976).

19 Nick Tosches, Unsung Heroes of Rock'n'Roll (New York: Charles Scribner's Sons, 1984), 57.

20Sheldon Harris, Blues Who's Who: a Biographical Dictionary of Blues Singers (New Rochelle, N.Y.: Arlington House, 1979), 86.

21 John Broven, "Roy Brown: Part 1-Good Rockin' Tonight," Blues Unlimited, no. 123 (January/ February 1977): 4. 
years later, in 1942, at the age of seventeen, Brown headed out to the West Coast with the intention of becoming a professional boxer. He was fairly successful, winning sixteen of eighteen welter-weight bouts, but the sight of blood made him physically sick, ultimately forcing him to abandon his boxing aspirations.

His first musical break came in Los Angeles in 1945 when he won an amateur singing contest at the Million Dollar Theatre singing Bing Crosby's versions of "San Antonio Rose" and "I Got Spurs that Jingle Jangle." Crosby was Brown's favourite singer at the time and remained so as late as 1975 , although curiously there are few traces of Crosby's influence on Brown's recordings. ${ }^{23}$ Brown won several other amateur singing contests in Los Angeles before he returned to Louisiana late in 1945 to work as a standup singer at Billy Riley's Palace Park in Shreveport. Riley's was an integrated club featuring a large show with a number of acts performing each night.

That's where I first learned to sing the blues. The first blues songs I ever learned [were] Buddy and Ella Johnson's "When My Man Comes Home" and Billy Eckstine's "Jelly Jelly." And I started singing these songs because the other singers on the show were doing the blues and the people were throwing their money. Dollar bills, half dollar bills, they were making pretty good tips. ${ }^{24}$

Earlier Brown had told his drummer, "I don't like the blues, I just won't sing them." 25 In addition to the blues, Brown's repertoire at the time consisted of a body of pop material such as "Stardust," "Temptation," "That Lucky Old Sun," "When They Ask About You" and Crosby's "Blue Hawaii," and "South Sea Island Magic." 26 As a black singer who could sound white he felt he was a novelty; the Elvis syndrome in reverse.

Brown stayed at Riley's Palace Park for nine months before moving on to a club in Galveston, Texas, where his ensemble played orchestrations of songs on the hit parade such as the Ink Spots' "If I Didn't Care" and Frank Sinatra's "A Lovely Way to Spend an Evening." Blues were not at first part of their repertoire in this particular club. ${ }^{27}$ Brown stayed at this job for four months before transferring to another Galveston nightspot, Club Grenada. For this new gig, he organized his own group comprised of tenor saxophone, guitar, piano, bass, and drums. Dubbed the Mellodeers [sic], the group's theme song was pop singer Jo Stafford's "There's No You." It was while working this engagement that Brown and the Mellodeers had the opportunity to broadcast regularly over radio station KGBC, the first black group on the radio in the Galveston area. ${ }^{28}$ Brown's best known song, "Good Rockin' Tonight," is a blues that was written

22Shaw, Honkers and Shouters, p. 101.

23 Ibid., 101.

24Broven, "Roy Brown: Part I," 5.

25 Ibid., 5.

26Tosches, Unsung Heroes, 57.

27 Broven, "Roy Brown: Part 1," 6.

28 Ibid., 6. 
while he was at the Club Grenada although, interestingly, he was singing only pop ballads on stage at the time.

I wrote a tune called "Good Rockin' Tonight" and we added a trumpet player to the group. His name was Wilbert Brown and when we did our radio show he sang "Good Rockin' Tonight" - I did all the ballads. And one particular day of the broadcast, he had an attack of acute indigestion and "Good Rockin' Tonight" was on the cue sheet, it was on the program. On the air, he just sat there and toppled over in his chair but the broadcast had to go on, so then the announcer said, "Here's Roy Brown and his Mellodeers and his new original 'Good Rockin' Tonight."' And the piano player looked at me and I gave him a signal to give me a shuffle rhythm in F. And I started singing, and boy, the fellas looked at me, they wanted to laugh because I started shouting! The announcer, the typist, they all came to the glass screen, they looked in to see who was the new singer. We got telephone calls after the broadcast, "Who was the new singer?" They didn't associate my voice with the falsetto-type thing as compared to my baritone, you see. And at the club that night they wanted the new singer to sing "Good Rockin' Tonight" so my trumpet player had recovered from his indigestion and said, "Man, I'm not gonna sing it, it's your number." I said, "No," and I wouldn't sing it until the boss made me sing it. ${ }^{29}$

Brown left Texas rather hastily when his intimacy with the club owner's wife was discovered. Back in New Orleans he approached Wynonie Harris about recording "Good Rockin' Tonight," but since he was not interested in hearing the song, one of his band members suggested taking it to Cecil Gant. Gant, although suitably impressed, elected not to record it himself, but to phone Jules Braun, the owner of Deluxe Records in New Jersey. Gant provided the introductions, Brown sang the song over the phone and a session was booked for a few days later when Braun was scheduled to be in New Orleans to record Paul Gayten and Annie Laurie. It was September 1947.

Because Brown was born in New Orleans and his first recording sessions were conducted in that city, writers such as John Broven have classified him as part of the New Orleans style of rhythm and blues, and have claimed that his version of "Good Rockin' Tonight" turned the national spotlight on New Orleans. ${ }^{30}$ This claim is questionable since Brown's version did not reach the national charts until June 1948. By then, ironically, Wynonie Harris had covered the song on the King label and achieved a much larger hit; this was doubly ironic since Brown would later record for King. But whatever the merits of this claim, classifying Brown as an exponent of New Orleans rhythm and blues is a mistake. Neither "Good Rockin' Tonight" nor any of Brown's other recordings display any of the characteristic trademarks that define New Orleans rhythm and blues. On none of Brown's recordings do the horns play the boogie rhythm with the piano, bass, and guitar. Nor do his records regularly feature cross rhythms, Caribbean influences, or a distorted emphasis on the low end of the sound spectrum, all trademarks of classic New Orleans rhythm

29 Ibid., 6.

30 John Broven, Rhythm and Blues in New Orleans (Gretna, La: Pelican, 1974), 21. 
and blues. On aural evidence, Brown's records could just as easily have been recorded in Texas, Cincinnati, or on either coast.

Although slow to gain acceptance nationally, Brown's version of "Good Rockin' Tonight" was extremely popular in New Orleans itself. Just prior to the record's release Brown had been earning four dollars a night at the Downbeat Club. A few weeks later his salary went up to ten dollars a night plus free board, and it was not too long before he was working for fifty dollars a night plus board at the Starlight Club. ${ }^{31}$ Brown eventually went on tour to promote the record with a six-piece band from New Orleans lead by trumpeter Teddy Riley. The rest of the band consisted of Leroy Rankins (tenor sax; nicknamed "the Batman" for his acrobatic playing feats on top of bars and tables), Louis Sargeant (alto sax), Tommy Shelvin (bass), Edward Santino (piano), and Frankie Parker (drums). Note that a guitarist was not part of his band at that time. "We only had six pieces, and then later I started using guitar because at this point I hadn't become as guitar conscious as I am now. My main thing was the tenor sax." 32

Brown performed on concert bills with a wide variety of nationally popular black artists including Billy Eckstine, Nat King Cole, Wynonie Harris, and Louis Jordan. His band was well rehearsed and would execute dance routines in matching stage suits. The only cover songs they performed were the old pop ballads that had made up the bulk of Brown's stage repertoire before "Good Rockin' Tonight." His band would usually warm up with ballads like Billy Eckstine's "Cottage for Sale," "I Apologize," "Jelly Jelly" and "Summertime," and Frank Sinatra's "Day by Day," "A Lovely Way to Spend the Evening," and "That Lucky Old Sun." "We used to jive it up and people would be frowning and say, 'I thought you did the blues.' But they didn't know I was warming up. Then I'd get into the blues." 33

King Records of Cincinnati bought his contract in 1950 when they purchased the rights to the whole Deluxe label. Within a year Brown stopped having chart hits. With the exception of a brief appearance with two covers in 1957, his last showing on Billboard's rhythm and blues charts was in January 1952. The hits stopped for a number of reasons. According to Brown, he was blackballed.

It happened in 1951. I had one of my biggest records "Big Town." That was a big one for me but right after that, that was when I discovered they were robbing me blind. And I went to my union and they fined all of them, and that's when they blackballed me. When I took them to the union they sent letters to all the different promoters around the country that I had become a dope addict, that I had beaten up my wife and kid-I didn't have a kid at that time. I'm not a violent man, I don't even smoke, but that was the word that was out. ${ }^{34}$

31 Broven, "Roy Brown: Part 1," 7.

32 Ibid., 10.

33 Ibid., 10.

34John Broven, "Roy Brown: Part 2-Hard Luck Blues," Blues Unlimited, no. 124 (March/June 1977): 15. 
Brown did not record for over a year after September 1951, and he was reduced to trying to book his own gigs through Mississippi, Alabama, Louisiana, and Texas on the strength of his early records, working just for the door. On week nights he would often have to guarantee to promote the shows himself. Then in December 1952, still under contract to King Records, his recording career resumed. Thirty-two songs were recorded over nine sessions through June 1955. All but two were released but none hit the charts. Given King's relative lack of interest in scheduling recording sessions for Brown, it seems doubtful that any of these releases were adequately promoted or distributed. Henry Glover, one of the few black men with an important role in the record industry at that time (he was the a \& $r$ man for King) offered another reason for the failure: Brown stopped having hits because he did not play a guitar.

I will say if Roy had been a guitarist, he would be as popular today as B.B. King, because in those days Roy was bigger than B.B. King and people said that B.B. sounded like Roy Brown. ${ }^{35}$

Although guitar appeared on his first session in the fall of 1947 in an accompanying role, and occasionally a guitar would play a response or riff during a tenor saxophone solo, no guitar solo proper appears on any of his records until "Teenage Jamboree" in 1950. Even then the guitar is only featured for eight measures, surrounded by tenor saxophone for sixteen and trumpet for a further eight measures. In addition, even though guitar solos regularly appear on his records in the 1950s, tenor saxophone and trumpet solos persisted right up until his last King Records session in 1955. In light of the above, it is interesting to note that the guitar solos and introductions heard on the later records were harmonically, rhythmically, melodically, and timbrally much more jazz-influenced than were the grittier, more repetitive, honking tenor saxophone solos. Brown, himself, said that "Nobody can last forever. I had reached the stage where some of my ideas were becoming obsolete." 36 Broven echoes this sentiment, suggesting that Brown's recordings had started to sound the same. This had been true from the beginning of his career and perhaps the public was tiring of his sound while, at the same time, King Records had him handcuffed, first by not recording him for over a year and then by not promoting and distributing his records to the best of their abilities.

For the purposes of this paper fifty-four of the seventy-four songs that Brown recorded from 1947 through 1955 were analyzed. This represents seventy-three per cent of his output in the pre-rock and roll period. Two jump songs, "Butcher Pete" and "Old Age Boogie," were recorded in two parts and released as both the "A" and " $B$ " sides of a seventy-eight. Each has been counted as only one song. Of the fifty-four available records, twenty-six are jump blues performances, six are medium tempo blues and twenty-two are slow tempo club blues. The jump blues appear in both 12- and 8-measure forms and

35 Steve Tracey, "King of the Blues: The Story of a Record Label Part 1," Blues Unlimited, no. 87 (December 1971): 7.

36Broven, "Roy Brown: Part 2," 15. 
three of the club blues, all recorded between June 1953 and May 1954, use the Tin Pan Alley aaba format of thirty-two measures. The remaining nineteen club blues recordings are in the more common 12-measure form. ${ }^{37}$

This initial division would seem to be based solely on tempo, and there is no denying that this has to be a central factor in any typology of Brown's repertoire. This is related, of course, to the group having to function as a dance band. Most of the jump tunes range between 150 and 180 beats per minute, the medium tempo blues range between 120 and 144 beats per minute, while the slower club blues are remarkably consistent at 66 to 78 beats per minute. It is clear that over an eight-year period, Brown and his accompanying musicians almost invariably associated these three different tempo ranges with three different types of songs. Naturally there are exceptions and some songs are at a tempo outside the range that is typical for a particular category. In these cases several other factors place the performance within the given category. For example, one club blues tune, "Special Lesson No. 1," moves at 90 beats per minute while "Midnight Lover Man," a slower tune at 82 beats per minute, is clearly a medium tempo blues. Similarly, three jump tunes- "Worried Life Blues" (quarter note=126), "Up Jumped the Devil" (quarter note=144) and "Old Age Boogie" (quarter note $=138$ )-all have tempos that are as slow as or slower than the fastest medium tempo blues. I would contend that both the band members and their audiences took into consideration factors other than simply tempo in categorising any given tune.

One distinguishing characteristic, especially with songs that in terms of tempo might seem to belong to a different category, is Brown's rate of singing. While the basic rhythmic pulse of the band will be at a certain tempo, Brown can choose to divide that pulse in eighths, in quarters or even in dotted quarters and half notes. The result is a different feel in each case and Brown's choice of division may be a better categorizing factor than the tempo of the basic pulses. In other words it may be more useful to place a tune in the same category as others with the same relative rate of singing, even though they may have different basic pulses. Equally important was the band's approach to how the time was articulated. Even the slowest of the jump tunes is underscored by an arpeggiated walking bass line played by both the piano and the string bass. One or more of the piano, bass, guitar, and drums on these jump examples always plays slightly on top or ahead of the beat whereas even the fastest of the medium tempo blues features a less arpeggiated bass line and a flatter approach to the rhythm, with notes neither pushing nor lagging behind but placed dead on the beat. The club blues, not surprisingly, have a much more laid back, often slightly behind-the-beat feel.

Other differences manifest themselves in the arrangements of the tunes. None of the club blues, and only one medium tempo blues ("Bootleggin' Baby," recorded in 1953), has an instrumental solo in it. On the other hand, every jump blues recording has at least one, and often two, solo choruses. In

37 See the Appendix for a listing of the tunes in their appropriate categories accompanied by date of release and tempo markings. 
general, solos on Brown's recordings during the eight years encompassed by this study are only one chorus long (although there are often two one-chorus solos in a given performance). All but two of the eight-measure jump tunes feature twelve-measure solos. The two exceptions, "Teenage Jamboree" and "Good Rockin' Man," have sixteen-measure solos. Similarly, not one of the medium tempo blues uses the devices of stop-time or two measure breaks ${ }^{38}$ for climactic effect whereas sixteen of the twenty-six jump tunes use these devices. Only four of the twenty-two club blues use stop-time or breaks. Several of the club blues do, though, have out of time (sometimes referred to as free rhythm) introductions or tags which serve a roughly similar function. When stop-time is used on the club blues examples, it usually does not appear until the second or third verse, thereby helping to prevent possible monotony. Five of the fifty-four tunes analyzed fade out at the end, something that was not at all common at the time.

Obviously elements of structure, arrangement and rhythmic approach, as well as tempo, serve to divide Roy Brown's recorded repertoire into these three distinct performance types. Instrumentation also plays its part. Drums are not prominent in Brown's 1947 and 1948 recordings; in fact, on one song, "Special Lesson No. 1," they are totally absent. On the early recordings the piano plays a large part in commenting rhythmically and laying out the time. By 1952, this had changed substantially. The drums assume a much greater role and the piano begins to function as a one-instrument equivalent of the horn section. Occasionally some interesting combinations were worked out such as the one heard on "Hard Luck Blues" from 1950 where triplets are played on both a ride cymbal and in dyads on the piano. The bass and the left hand of the piano generally played arpeggiated, walking four- or eight-to-the-measure bass lines; on the slower club blues these are often chromatic. On some jump blues, "Good Rockin' Tonight" for example, the bass plays slightly ahead of the piano, accentuating the jump feel. The right hand of the piano and the horn section play riffs and/or fills either behind or between vocal phrases. These riffs and/or fills were usually played over a triplet grid ${ }^{39}$ which is not surprising given the jazz environment from which both the players and the idiom came. The backgrounds provided by the horns and piano often change from verse to verse, in terms both of who is featured and what type of riff is actually played.

Lyric content can also help us classify Brown's recordings. Club blues lyrics commonly evoked a high level of pathos. One need only look at the titles of Brown's club blues examples to see this: "Hard Luck Blues," "End of My Journey," "Double Crossin' Woman," "Wrong Woman Blues," "Lonesome

38 Break refers to a break in the prevailing texture. Commonly all instruments but one (usually the vocal) stop playing for approximately two measures. Stop-time is a special type of break in which the prevailing texture is replaced by one or more instruments playing a repeated staccato rhythmic figure in each measure. These stop-time figures are commonly short (e.g., playing on just beats 4 and 1 or playing the off-beat before one and then one).

39 Triplet grid refers to the subdivision of each beat in $4 / 4$ time into triplets. This is often termed $12 / 8$ time in discussion of other musics. In popular music and jazz studies of this sort triplet grid is used to underscore the fact that much of the ensemble is still articulating the basic parts of a $4 / 4$ groove (e.g., the backbeat). 
Lover," "Laughing but Crying," and "Trouble at Midnight" are but a few sample titles. Typically, the last verse of these tunes is the most desperate or despondent. A good example is "Fore Day in the Morning."

Well it was 'fore day in the morning, the blues got in my bed,

I screamed out loud, "Oh Lord, I wish that I was dead!"

Oh, 'fore day in the morning my baby caught that 'fore day train,

Well, the tears came streaming down, 'cause I know we'll never meet again

Other important recurring themes in the club blues material are time ("Long About Midnight," "End of My Journey," "Trouble at Midnight," "Long About Sundown"), dreaming ("Brown Angel," "Dreaming Blues," "Fore Day in the Morning"), being lonesome ("This Is My Last Goodbye," "Lonesome Lover," "Sweet Peach"), crying out to the Lord ("Brown Angel," "Laughing but Crying") and death ("Double Crossin' Woman," "Long About Midnight," "Black Diamond," "End of My Journey").

In direct contrast, the jump blues tunes more often evoke the good times. Obvious examples include "Good Rockin' Tonight," "Roy Brown's Boogie," "Boogie at Midnight," "Teenage Jamboree" and "Caldonia's Wedding Day." A casual perusal of the jump blues titles might seem to indicate some down or sad tunes, but on closer examination these often turn out to be in the humorous, novelty vein, described earlier in reference to Louis Jordan. These commonly have themes centred on the battle of the sexes, and include such songs as "Up Jumped the Devil," "Grandpa Stole My Baby," "Whose Hat Is That," and "Letter From Home." Verse three of "Grandpa Stole My Baby" will make this clear:

Well, he ain't got no money, 'way past his prime,

Mother Nature's gone thanks to Father Time,

Whatever he does, baby likes it well,

Doggone hustler, that woman won't tell.

Grandpa stole my baby (x 3), stole the woman I love and gone.

Typically the jump tunes also display a fair amount of braggadocio, usually exhibited in Brown's claims to virility and/or threats to his partner if she does not treat him right. The fifth verse from "Whose Hat Is That" is a representative example:

Yes, little Roy Jr. said a man was here last night,

And when he got here you turned out all the lights,

Now, woman, you tell me, whose hat is that?

Well, don't tell me no lies, I'm holding this baseball bat.

Other typical jump blues themes include trains ("Hurry Hurry Baby," "Roy Brown's Boogie," "Train Time Blues," "Miss Fanny Brown Returns"), age ("Old Age Boogie," "Mighty Mighty Man," "Grandpa Stole My Baby"), and rock, both in a musical sense and as a euphemism for sex ("Teenage Jamboree," "Bar Room Blues," “Ain't No Rockin' No More," "Good Rockin' Tonight”). 
An important lyric structural element that distinguishes Roy Brown's material from that of many of his contemporaries is the use of four-line forms alongside the standard two-line $a a b$ form. In nearly all of the songs that use the device, stop-time appears whenever Brown resorts to a four-line stanza. The most common arrangement has the first two or three verses in the standard $a a b$ form with the last two verses having four lines each. The first of these later verses is typically where stop-time will first appear. The change in both music and lyric structure at these points serves a climactic function, incorporating into the song a completely new level of information, interest and excitement. This type of device is used in all three types of song in Brown's repertoire. Few of his songs follow the $a a b$ form all the way through but all of them use that form for at least one verse and nearly all of them start with at least a single $a a b$ stanza. Four-line stanzas are, not surprisingly, the rule for the eight-measure jump tunes, often followed by a chorus which utilizes the form $a a a b$ ("Grandpa Stole My Baby", quoted above, is an example). Brown often simply repeats the same line three times in the twelve-measure form ( $a a a)$ for the last one or two stanzas of a given twelve-measure jump song. This may be seen in the concluding verses of "New Rebecca" and "Roy Brown's Boogie," and was a technique commonly employed by Brown's contemporary Wynonie Harris.

It was probably as a singer that Brown was most influential. Elements of the styles of B.B. King, Roy Hamilton, Clyde McPhatter, Jackie Wilson, Chubby Checker, Ted Taylor, Billy Wright, and the earliest recordings of Bobby Bland and Little Richard exhibit a clear Roy Brown influence, particularly his high, melismatic, cry-like trademark. Per Notini believes that Brown was the first person to take from gospel its intensely emotional delivery and as a result calls Brown the first soul singer. This passionate style was quite new to secular popular music and immediately distinguished Brown from the shouters of the time such as Big Joe Turner and Wynonie Harris. ${ }^{40}$ Jonas Bernholm feels that Brown pioneered a new and unorthodox style. Writing about both Brown and Elvis Presley, he says that the two singers "embraced a free-flying spirit unrestricted by conventional values ... In a word they rocked and their voices became instruments of youthful optimism during an era of seemingly unlimited possibilities." 41 Nick Tosches also sees Brown as "one of the first real rock and roll voices" 42 while Arnold Shaw writes of Brown singing in a "cry" style rather than the then prevailing "shout" style. One of Brown's strengths, according to Shaw, was that he could sing the blues with a pop expression while he could also deliver a pop ballad à la Bing Crosby and Frank Sinatra. ${ }^{43}$ Charlie Gillett suggests that "much more direct contributions to the vocal style of rock'n'roll were made by singers who cried rather than shouted the blues." $44 \mathrm{He}$ implies that this cry style came from the church and he considers that Roy Brown pioneered the technique that was later copied by Larry Darnell, B.B. King,

40Per Notini, liner notes for Good Rockin' Tonight (Sweden: Route 66 Records 1978).

41 Bernholm, liner notes for Roy Brown, 1925-1981: Saturday Night.

42Tosches, Unsung Heroes, 58.

43 Shaw, Honkers and Shouters, 102.

44Gillett, Sound of the City, 130. 
Junior Parker, Johnny Guitar Watson, Bobby Bland, James Brown, and Little Richard. For Gillett the shouting singers always seemed in control of their voices whereas Brown's voice was shaped by the passions of the particular song that he was singing. "Rocking frantically to a boogie beat, or wracked by desolate doubt, he committed all he was to the song's message." 45

None of these writers actually says what this "cry" style consists of but it is possible to deduce this from Brown's recordings. He characteristically starts phrases with a high, soaring vibrato-laden "Well ... " He nearly always sings this on a G-flat, usually the highest note of the performance, which he uses whether the key is A-flat, E-flat or G-flat. Brown will hit these high soaring notes clear as a bell and then swell on them, producing a sound like that of a siren. A casual listening to records from all categories of his repertoire will reveal that this device is used in the vast majority of his performances. On some songs he will use vocables and sing the same type of figure during an instrumental solo or a tag. "Good Man Blues" contains a fine example of this. This device obviously functions as an identifying trademark for Brown. Elvis Presley was to sing this same high, held "Well..." on a very large number of his early recordings and through his influence, Brown's trademark became an identifying feature of rockabilly.

Brown is much smoother than most of his contemporaries in the way that he slides while connecting notes over rather large interval leaps, even when two subsequent intervals have their directions reversed. His individual phrases often have a characteristic contour, starting high and then descending, and he also makes liberal use of melisma and vibrato even on the fastest of the jump blues recordings. Vibrato is often an integral part of his trademark siren-like "Well...", increasing in speed or getting wider the longer he holds the note. All of these characteristics contribute to this so-called "cry" style. Brown's enunciation is very precise and clear and he uses this ability to create interest on the faster jump tunes such as "Grandpa Stole My Baby" where the melody is simple and repetitive. His intonation is also extremely precise and he phrases quite freely against the beat, commonly placing notes an indeterminate degree later or earlier than the beat. This freedom of phrasing against or across the basic pulse is characteristic of all the finest rhythm and blues and rock and roll singers.

Notini suggests that Brown's melodic sophistication and rhythmically free style of phrasing were two of the factors that stopped him from enjoying continued success during the rock and roll era, ${ }^{46}$ but one only has to listen to the complexity evident on Elvis Presley's early recordings to realize that this is patently false. Presley regularly employed large interval leaps and phrases continually against or across the basic time pulse and it seems certain that this is a consequence of Brown's influence. Obviously one could sing rock and roll in this style and be very successful. Brown's failure in the rock and roll era

45 Ibid., 131.

46Notini, Good Rockin' Tonight. 
was probably due more to limitations in his song writing, lyrics, instrumental backing, and image.

Brown's influence was pervasive. B.B. King used Brown's "Fore Day in the Morning" as his theme song when he was a disc jockey on WDIA in Memphis and there is more than a casual relationship between that song and King's first hit, "Three O'Clock Blues." When Jackie Wilson's recording of "Lonely Teardrops" was first released, it was, according to Broven, widely mistaken for a new Roy Brown record. ${ }^{47}$ Finally, it is hard to imagine Elvis Presley's "Heartbreak Hotel" sounding as it does without Roy Brown having been there first. Brown's cry style, influenced by the gospel music of the black church, was grafted on to two of the three most prevalent currents of post-war rhythm and blues-jump blues and club blues. Up to now these styles have been unduly neglected by scholars and hobbyists alike. Hopefully this paper helps to further define these styles while shedding light on the career, style, and influence of one of the most important exponents of post-war rhythm and blues.

\section{Appendix: Classification of Repertoire}

\section{Twelve-Measure Jump Blues}

Song Title Date of Recording Beats per minute

\begin{tabular}{lll}
\hline Good Rockin' Tonight & 1947 & 152 \\
Whose Hat Is That & Oct. 1947 & 168 \\
Miss Fanny Brown Returns & 1948 & 156 \\
Roy Brown's Boogie & 1948 & 186 \\
Mighty Mighty Man & 1949 & 210 \\
Boogie at Midnight & 1949 & 180 \\
New Rebecca & April 1950 & 150 \\
Good Man Blues & June 1950 & 162 \\
Train Time Blues & June 1950 & 162 \\
Bar Room Blues & June 1950 & 156 \\
Beautician Blues & June 1950 & 144 \\
I've Got the Last Laugh Now & Jan. 1951 & 168 \\
Old Age Boogie & Dec. 1952 & 138 \\
Letter From Home & Dec. 1952 & 150 \\
Hurry Hurry Baby & Dec. 1952 & 216 \\
Mr. Hound Dog's In Town & March 1953 & 168 \\
Caldonia's Wedding Day & June 1953 & 180 \\
Ain't No Rockin' No More & May 1954 & 196 \\
Up Jumped the Devil & April 1954 & 144 \\
Worried Life Blues & Sept. 1954 & 126
\end{tabular}


Eight-Measure Jump Blues

Butcher Pete Parts 1 \& 2

Nov. $1949 \quad 180$

Love Don't Love Nobody

June 1950

156

Teenage Jamboree

June 1950

146

Good Rockin' Man

Jan. 1951

150

Grandpa Stole My Baby

Dec. 1952

162

Black Diamond

Sept. 1954

180

\title{
Medium Blues
}

Rainy Weather Blues

1948

144

Big Town

Jan. 1951

126

Money Can't Buy Love

Dec. 1952

132

Midnight Lover Man

Dec. 1952

82

Everything's Alright

Dec. 1953

135

Bootleggin' Baby

Dec. 1953

120

\section{AABA Pop Tunes}

A Fool in Love

June 1953

66

This is My Last Goodbye

April 1954

72

Ain't It a Shame

May 1954

Slow Tempo Club Blues

Special Lesson No. 1

1947

90

Long About Midnight

1948

78

Fore Day in the Morning

1948

78

End of My Journey

Hard Luck Blues

Sept. 1949

78

April $1950 \quad 72$

Sweet Peach

April 1950

78

Dreaming Blues

Long About Sundown

June 1950

78

June $1950 \quad 78$

Double Crossin' Woman

June 1950

78

Wrong Woman Blues

Jan. 1951

66

Brown Angel

Sept. 1951

72

Lonesome Lover

Sept. 1951

66

Travelin' Man

Dec. 1952

66

Laughing But Crying

June 1953

66

Trouble At Midnight

Dec. 1953

66

Queen of Diamonds

May 1954

66

\begin{abstract}
The classification of different styles of North American popular music has often been problematic. This paper investigates some of the music referred to as rhythm and blues (r \& b) in the late 1940 s and early 1950 s by specifically looking at the works of one of the music's leading practitioners of the time, Roy Brown. Brown recorded both jump and club blues between 1947 and 1955, placing fifteen records in the Top 20 of the Billboard rhythm and blues charts.
\end{abstract}


For the purposes of this paper fifty-four of the seventy-four songs that Brown recorded in this period were analyzed with respect to structure, performing force, performance style, tempo, arrangement, bass lines, approach to the beat, rate of singing, vocal ornamentation, and lyric content and structure. Three main subdivisions were found within Brown's repertoire, all connected to social behaviour, namely, dance. In the process, a basic biography of Brown is provided and his influence on many subsequent rhythm and blues and rock and roll performers is contextualized. 